\title{
CAUSAS Y FACTORES POSIBILITADORES DEL PROCESO MIGRATORIO EN EL DISCURSO DE LOS EMIGRANTES: GALLEGOS EN CUBA EN LA PRIMERA MITAD DEL SIGLO XX ${ }^{1}$
}

POR

\section{JOSÉ ANTONIO VIDAL RODRÍGUEZ}

Miembro del Seminario de Fuentes Orales de la Universidad Complutense de Madrid

En este artículo intento destacar, basándome en diferentes tratadistas de los siglos XIX y XX y en testimonios orales recogidos en Cuba, cómo además de las causas económicas actuaron también, y con frecuencia decisivamente, otros factores de tipo psicosocial en la decisión migratoria de muchos de los gallegos que emigraron a Cuba, sin los cuales, probablemente, nunca se hubiesen decidido a abandonar sus hogares. Hecho que bien se podría hacer extensivo a los demás procesos migratorios de otras regiones de España durante el período de emigración masiva de españoles hacia América.

Palabras clave: Galicia, Cuba, historia oral, causas y factores migratorios.

\section{LA EMIGRACIÓN GALLEGA A CUBA}

Galicia fue la región española que más emigrantes aportó al proceso migratorio español transoceánico de los siglos XIX y XX. La gran mayoría de éstos se dirigió a Argentina y $\mathrm{Cuba}^{2}$. Entre 1899 y 1960 llegaron a Cuba unos 378.000 inmigrantes procedentes de Galicia, lo que representó el $45 \%$ del total de la emigración española a la isla. Los mayores contingentes llegaron en el

1 Este artículo forma parte de una investigación más amplia sobre el proceso migratorio gallego a Cuba durante la primera mitad del siglo XX, basada, además de en fuentes documentales y hemerográficas, en 145 historias de vida de viejos inmigrantes gallegos recogidas personalmente en diferentes provincias cubanas entre los años 1997 y 2000.

2 Sánchez-Albornoz, 1988. Eiras Roel, 1991. Yáñez, 1994. 
primer tercio del último siglo y tenían como meta las zafras cubanas y los numerosos puestos de trabajo que esta actividad agroindustrial demandaba por entonces. Los contingentes migratorios seguían el ritmo del precio del azúcar, cesando momentáneamente cuando se producía alguna crisis azucarera. Pero, si en un principio la mayoría de los emigrantes gallegos, como el resto de los peninsulares, acudió a la llamada de la agricultura y de la industria del azúcar, los que viajaban a través de cadenas migratorias familiares y locales, mayoritarios a partir de 1921, se insertaron en los rubros económicos controlados por sus familiares y vecinos en la isla: comercio de víveres, pesca, hostelería y restauración, cultivo y tostado del café, tintorerías, casas de préstamo y empeños, mueblerías, cultivo y venta de flores y jardinería, así como en otros nichos y enclaves laborales que dominaban parcial o totalmente sus paisanos. Las mujeres, que fueron numerosas a partir de 1920, se emplearon preferentemente en el servicio doméstico de La Habana, labor para la que eran preferidas a las propias cubanas 3 .

Los mayores contingentes llegaron en el primer tercio del siglo pasado. A partir de la crisis económica mundial de 1929 cesaron los grandes flujos migratorios, retornando a su región natal gran número de los expulsados de la isla por el paro producido por la crisis y por la xenófoba Ley de Nacionalización del Trabajo de 1933. Con todo, a partir de 1946, una vez restablecida la paz mundial y la economía cubana, las cadenas migratorias gallegas hacia la isla, hasta entonces dormidas, comenzaron a reactivarse, hasta que el triunfo de la revolución de 1959 acabó por extinguirlas.

Las causas tradicionales de la emigración masiva de los gallegos hacia Cuba

Múltiples y variadas son las causas que empujaron a los gallegos a emigrar masivamente al otro lado del océano, y concretamente a la isla de Cuba. En la segunda mitad del siglo XIX, cuando se iniciaba este éxodo transatlántico, la miseria del campesinado gallego era considerada por los poetas Rosalía de Castro $^{4}$ y Curros Enríquez 5 la causa principal de la emigración masiva de sus paisanos al Nuevo Mundo. En el primer tercio del siglo XX seguía siendo «la vida hambrienta y mal retribuida de la labranza» el principal factor de expulsión del campesinado gallego según el agrarista Valeriano Villanueva ${ }^{6}$, y según también muchos de los testimonios recogidos en Cuba:

\footnotetext{
3 Vidal Rodríguez, 2005.

4 Castro, 1968. Rodríguez, 1988.

5 Ferreiro, 1976.

6 Villanueva, 1984: 272.
} 
Allá teníamos terrenos pequeños: viñas, maíz, papas, centeno, y verduras. Trabajábamos para comer en el año ... Nosotros éramos siete hermanos y trabajábamos las pocas tierras que teníamos. A mí no me da pena decir que yo vine mayormente a abrirme paso, porque allí se trabajaba mayormente para comer. (E núm. 16. Antonio: 1908 Carballeda de Avia-OR> 1922, La Habana, 8/12/97).

Así pues, como sostenía en 1930 el nacionalista Vicente Risco, todos los que emigraban pretendían «mellorar de fortuna» ${ }^{7}$. Esta necesidad de «mejorar» fue la que también obligó a Ramón, campesino de Castrelo de Val, a embarcarse hacia la Gran Antilla en 1919:

¡Figúrese! Yo vine a Cuba por el instinto de mejorar. Porque yo soy de una familia, no pobrecitos, pero pobre; agricultores de una aldea y ese negocio. Y como vino muchísima gente de la aldea, yo me animé también (...). Yo me recuerdo que mi padre me escribía cuando la revolución española: -Aquí no quedamos más que los ancianos y los niños, porque la juventud emigró toda. (E núm. 42. Ramón: 1903 Castrelo de Val-OR> 1919, Las Tunas, 31/7/99).

Todavía a mediados del siglo XX, nada más acabar la Segunda Guerra Mundial, cuando se reiniciaba la emigración masiva ultramarina, la necesidad continuaba siendo la causa principal de la decisión migratoria de los gallegos que se embarcan hacia Cuba:

Yo vine por las necesidades que había allí. Yo vivía en una aldea que no tenía más que campo, y el campo allí daba muy poco. La vida allí estaba muy mal. No se podía comer, no se podía vestir. Teníamos muy pocas tierras, y muy malas. Aquello es un desfiladero que eso es tremendo, aquello da miedo. Al lado del río, un poco de vino, en las lomas del desfiladero un poco de castaño, y arriba, ya en el pueblo, lo poco que se podía arar y los prados para los animales. ¡Figúrese usted! En esos años cuarenta se vivía muy mal, el pan no se veía ni por asomo. (E núm. 71. José: 1922 Parada de Sil-OR> 1949, Santa Clara, 5/5/98).

Otros tratadistas de la emigración gallega ultramarina, como el anarquista Ricardo Mella, culpan a la extrema subdivisión de la tierra de ser una de las principales causas del éxodo de sus paisanos; minifundismo sin el que, decía, «la emigración no existiría $»^{8}$. Son muchos los entrevistados que apuntan esta tradicional subdivisión de la propiedad familiar como causa de su propia decisión de emigrar; como Antonio, natural de Nogueira de Ramuín:

Mis padres eran campesinos pobres, vivían de la tierra (...). En Nogueira de Ramuín hay mucha tradición de paragüeros y afiladores (...). Allí hay poca tierra y está muy dividida y no daba para vivir. Nosotros éramos cinco hermanos, cuatro hembras y yo, y la herencia la tuvimos que dividir entre los cinco. A mí me tocaron cinco parcelas de tierra, y a mis hermanas las mismas. La tierra producía lo necesario

\footnotetext{
7 Risco, 1976: 62.

8 Mella, 1934.
} 
para vivir; se cosechaban castañas, la patata, las legumbres, el maíz y lo necesario para vivir justito. Por eso se hacía necesario salir en la época que se acaban las cosechas, para sacar algunas pesetas para comprar otras cosas, como la ropa, el calzado y los productos de la tienda. Y por esa situación tuve que venir a trabajar a la joyería de mi tío en Santa Clara. (E núm. 79. Antonio: 1936 Nogueira de Ramuín-OR> 1951, Santa Clara, 2/5/98).

Pero, la herencia igualitaria entre los hijos no era norma general en toda Galicia. También la costumbre de dejar al hijo mayor toda la propiedad, arraigada en ciertas comarcas del centro y este de la provincia de Lugo, parece que empujó a muchos jóvenes campesinos desheredados a emprender el trayecto migratorio hacia Cuba. Éste fue el caso de José de Castroverde y el de la familia de Aurora de Palas de Rei:

En ese tiempo allí, como en toda la provincia de Lugo, heredaba el que se quedaba en la casa. Él era el que repartía, pero allí había poco que repartir. Los demás echaban un pie y salían de la casa. Se iban a Madrid, para Barcelona, a trabajar a las minas de Asturias, o a Cuba, como yo. El que se quedaba en la casa era el que las trabajaba. (E núm. 1. José: 1907 Castroverde-LU> 1924, La Habana, 24/11/97).

Mi mamá se casó con mi papá que era hijo de labradores fuertes y ella era pobre, y usted ya sabe cómo era eso allí. El que se quedó con la casa y las tierras fue el hermano mayor de mi papá y nosotros nos quedamos pobres. Éramos cinco hermanos y para que pudiéramos vivir mejor mi mamá decidió venir a Cuba con mi hermana mayor para trabajar y mandarnos los ahorros. Luego vinimos los demás. (E núm. 23. Aurora: 1914 Palas de Rei-LU> 1925, La Habana, 10/2/98).

No obstante, además de estas causas económicas, los testimonios de los inmigrantes entrevistados aducen con frecuencia motivaciones de tipo familiar, psicológico o estrictamente personales. La huida del servicio militar fue el motivo más frecuente entre los hombres jóvenes a la hora de decidirse a emigrar antes de 1928. Los que iban a entrar en quintas trataban de huir de la movilización militar al conflicto marroquí, como sostiene el Manifiesto de Solidaridad Gallega de 1905: «La facilidad de marchar a América y el estímulo de hacerlo para esquivar el servicio del Rey fueron dando preferencia general y decidida a nuestros emigrantes por la América Latina» ${ }^{9}$. La objeción al servicio militar aumentaba alarmantemente en los momentos de mayor conflicto militar en Marruecos, cuando más jóvenes se decidieron a embarcar clandestinamente hacia Cuba:

Yo vine para acá en el año once. Nada más cumplir los trece años me mandaron para Cuba, para no tener que ir al servicio militar; que entonces se llevaban a los muchachos a Melilla. (E núm. 145. Manuel: 1897 A Peroxa-OR> 1911, Holguín, 2/8/97).

\footnotetext{
9 Manifiesto para la Solidaridad Gallega, 1907: 14.
} 
Yo vine a Cuba porque unos tíos que tenían comercio me llamaron, porque si no tenía que ir al servicio militar, a la guerra de Marruecos. Cuando el 21 había sido muy malo, mucha juventud murió allá. Y entonces mi familia me dijo: - Bueno, pues ahora sólo te queda irte para Cuba, a Argentina o a los EEUU. Y como en Cuba tenía a los tíos y en los otros países sólo algún vecino, pues me vine para acá. (E núm. 4. Augusto: 1906 Santa Marta de Ortigueira-C.> 1925, La Habana, 25/11/97).

Yo vine huyéndole a la guerra de Marruecos, como vinieron muchos españoles. De aquella estaba eso muy duro. Y debido a eso yo salí de España, y como yo muchos. El que no pudo salir legal, salió a fuerza de dinero, pero salió. (E núm. 40. José: 1904 Coristanco-C.> 1924, Trinidad, 7/7/99).

Sin embargo, no resultaba fácil burlar los controles legales sobre los quintos que pretendían embarcarse hacia América, de manera que muchos tuvieron que viajar con el nombre y la fecha de nacimiento cambiada, e incluso algunos tuvieron que acudir a picarescas tan novelescas como la de vestirse y adoptar la personalidad del sexo opuesto con el fin de poder engañar a los inspectores de emigración de los puertos:

Vine con el nombre cambiaó, porque era menor de edad, tenía 16 años ... Vine para librarme del servicio militar, que decían que trataban muy mal a los soldados. (E núm. 101. Manuel: 1914 Amoeiro-OR> 1930, La Habana, 3/3/1998).

Un primo mío estaba comprendido en quintas y se escapó y vino para Vigo, e iba a embarcar para aquí, y cuando fue a la casa consignataria, le estaba esperando la guardia civil, y desde allí cogió para atrás, por las montañas esas, y se fue a pie hasta Rivadavia y estuvo por allá escondido. Y entonces ese mismo lo embarcó ¿Y sabe cómo lo embarcó? Vestido de hembra ... junto con otro macho, como pareja, sabe. Porque todos no vinimos de la misma forma. (E núm. 16 Antonio: 1908 Carballeda de Avia-OR> 1922, La Habana, 8/12/97).

Pero no se huía de las quintas en soledad, por lo general la decisión era colectiva, con un grupo de mozos de una misma parroquia o comarca rural. Unos arrastraban a otros ante la angustia de ser destinados al frente marroquí, y de perder así los mejores años de la vida improductivamente, o incluso la propia vida, cuando su pobre economía familiar más necesitaba su contribución laboral:

Yo me embullé por el servicio. Tenía que ir al servicio, y de aquella había guerra en Marruecos, que morían muchos soldados españoles, porque a los españoles no nos dejaban matar moros, había que civilizarlos (...). Yo de aquella sólo tenía dieciséis años, pero si aguardaba a tener dieciocho o diecinueve ya entraba en quintas. De aquella los jóvenes no queríamos hacer el servicio militar, sobre todo los pobres, los del campo, porque los ricos, esos iban para la capital. Pero a los que estábamos en Galicia y eso, nos mandaban para Marruecos. Así que le dije al viejo: — «Yo no voy para Marruecos, me voy para Cuba». Vinimos como ocho o diez muchachos, vecinos míos, todos los quintos de allí. (E núm. 100. Jesús: 1904 Gomesende-OR> 1920, Morón, 3/12/97). 
No todos los prófugos fueron empujados por acuciantes necesidades económicas, algunos de ellos pertenecían a familias campesinas con un cierto desahogo económico, quienes, como Antonio de Puentedeume, sin la inminente amenaza del servicio militar en Marruecos difícilmente hubiesen iniciado su trayecto migratorio:

En 1920 me vine con unos jóvenes conocidos de Puentedeume (...). Yo, lógicamente, no tenía necesidad, porque teníamos muchas tierras para trabajar. Nosotros sembrábamos de todo, teníamos un hórreo y se llenaba todos los años. Vivíamos muy bien, en una casa muy linda, con una parra de uvas, y por el centro de la finca pasaba el camino real (...). Yo vine huyéndole al servicio militar. Antes de cumplir los veinte años yo salí de España, porque si no me tocaba el servicio y tenía que ir donde ellos querían. (E núm. 98. Antonio: 1902 Pontedeume-C, 1920, Sagua la Grande, $5 / / 5 / 98)$.

El conflicto marroquí terminó en 1927 con la detención de Abdelkrim, caudillo de la rebelión rifeña. A partir de entonces, y a lo largo del período republicano, fueron remitiendo las huidas transatlánticas de prófugos. De modo que la mayoría de los jóvenes quintos decidieron cumplir con sus deberes militares, como lo testimonia Francisco, natural de Valdoviño, quien decidió posponer su marcha a Cuba hasta cumplir el servicio de armas.

El segundo de mis hermanos vino huyéndole al servicio militar. Pero cuando yo vine ya no había guerra de África, y por eso quise cumplir con el servicio. En el año de 1935 llegué aquí, con 25 años. Hice el servicio antes de venir a Cuba. Así que no le debo nada a España, le serví al rey y a La República, a Azaña. (E núm. 43. Francisco: 1909 Valdoviño-C> 1935, Santa Clara, 1/5/98).

Con todo, ni las condiciones económicas ni tampoco la objeción al servicio militar fueron las causas exclusivas de la decisión migratoria. La pobreza era común a la mayoría de los campesinos gallegos hasta la segunda mitad del siglo XX, sin embargo, no todos emprendieron el camino de la emigración, y de los que emigraron no todos tuvieron el mismo destino. La decisión de emigrar y la elección de país de destino dependieron en muchas ocasiones de la influencia determinante de los vecinos y familiares retornados, lo que el agrarista nacionalista Villanueva denominaba el «contagio», gracias al que, decía, «los campesinos van unos detrás de otros, todavía más que los propios señoritos en sus modas» ${ }^{10}$. Frecuentemente la pretendida inducción, el «embullo» - según la terminología cubana empleada por los entrevistados-, procedía de familiares o amigos, que con sus historias, más o menos fantásticas, inducían a emigrar a algunos jóvenes deseosos de ampliar los estrechos horizontes de sus

10 Villanueva, 1984: 273. 
parroquias rurales. Éste fue el caso de Carmen de Sarria y de María de A Estrada:

Mis padres eran labradores. Nosotros trabajábamos nuestras propias tierras. Dos de mis hermanos vinieron para aquí, y entonces ellos estaban yendo allá a cada rato, y me contaban esto y aquello, y me fueron entrando ganas de irme con ellos. Y en uno de esos viajes yo le caí a uno y le dije: — «Ay, yo quería ir a Cuba», y me dijo: - «Yo te voy a mandar llamar». Y entonces me llamó y me vine para Cuba con una señora que venía para acá, que era de por allá. Ella se hizo responsable de mí, porque yo era menor. (E núm. 66. Carmen: 1905 Sarria-LU> 1923, La Habana, 24/10/97).

Me animé a venir a Cuba porque allá trabajábamos mucho. Yo salía al jornal ya de chiquitica. Yo tenía diez años y ya salía a trabajar en el campo. Y trabajaba mucho. A mí me buscaban para trabajar porque yo era una muchacha que trabajaba sin mirare. Y entonces, tanto trabajo, y siempre luchando, y me empezaron las amigas a embullar, porque algunas venían para acá de visita. Así que yo me decidí también a venir. Y me dijo mi mamá: — «Mi hija, tú quieres irte y yo no quiero quitarte la idea. ¡Vete! A ver si tienes más suerte que aquí». Y me fui y más nada. Me vine con esas tres amigas, una ya estaba en La Habana trabajando de sirvienta, fue la que nos animó. (E núm. 12. María: 1904 A Estrada-PO> 1929, La Habana, $6 / 4 / 98)$.

Cuando las historias fantásticas y los «cuentos de caminos» no eran suficientes para animar a los menos ingenuos, la presencia del indiano enriquecido en la comarca hacía soñar a muchos jóvenes campesinos sin expectativas de futuro; a pesar de que muchas veces la riqueza que manifestaba el pretendido triunfador retornado fuera pura fantasía. Aun así, fueron muchos los jóvenes gallegos empujados a Cuba por el ejemplo y la emulación de algún rico indiano retornado a sus contornos. Así, de Justo Díaz Rodríguez, natural de Becerreá, uno de los inmigrantes gallegos más ricos de Cuba a mediados del siglo, cuenta el libro Españoles en Cuba que emigró a la isla empujado por el ejemplo de un afortunado emigrado del pueblo vecino de Triacastela, quien en 1909, cuando Justo era un pastor huérfano de 19 años, regresó a su aldea natal después de haber amasado una cuantiosa fortuna en Perico (Matanzas), difundiéndose la noticia por toda la comarca, llegando incluso a su aldea de Guilfrey. El joven Justo, como relata su panegirista, acudió a la fiesta que el rico indiano dio a sus paisanos en su aldea, y:

«... aprovechando la euforia del acontecimiento, el joven pastor, audaz y emprendedor, visitó al recién llegado, exponiéndole sus anhelos de trasladarse con él a Cuba, pues al igual de muchos de sus compatriotas vislumbraba en la Perla de las Antillas un ambiente propicio a la realización de sus sueños (...) Al emprender este viaje que colmaba sus ilusiones, don Justo, que tenía a la sazón 19 años, acariciaba el sueño de volver rico un día a su pueblo y de asegurar la felicidad de su bondadosa madre y de sus hermanos». 
Don Justo emigró a Cuba protegido por este indiano vecino, y tras varios años de penalidades y fracasos económicos logró construir un imperio comercial e inmobiliario en Elia (Camagüey), regresando como triunfador a su aldea en 1925, reproduciendo el espejismo del indiano que 16 años antes le había empujado a emigrar:

«Al llegar a Becerreá alquiló un caballo para transportar sus equipajes hasta su aldea natal de Guilfrey. (...) se desbordó la alegría en el pueblo por tan grata sorpresa, congregándose todos los habitantes para felicitarle y darle la bienvenida. Al mes de su llegada, obsequió a todo el vecindario del pueblo con una magna fiesta que principió con una misa solemne en la Iglesia Parroquial. Se celebró una procesión a los acordes de una banda de música, y durante tres noches consecutivas se prolongó el festejo con toda clase de diversiones y bailes. Careciendo Guilfrey de alumbrado eléctrico tuvo don Justo el acierto de hacer instalar una espléndida iluminación al estilo veneciano, con típicos farolillos verbeneros» ${ }^{11}$.

Sin duda, estos fastos indianos empujaron a otros jóvenes de la comarca de Don Justo a emigrar a la Perla de las Antillas, y como él, fueron muchos los jóvenes gallegos que también se decidieron a emigrar a Cuba para emular el trayecto de algún afortunado indiano retornado a su vecindad. Todavía a principios de los años cincuenta, la llegada a la comarca de uno de los emigrantes triunfadores con toda la parafernalia del indiano enriquecido - gran coche americano, trajes impecablemente blancos y prendas de oro- era capaz de convencer a los más jóvenes y desesperados que el oro corría por las calles y campos de la isla, como cuenta el actual presidente de la Beneficencia Gallega de La Habana, natural de una aldea vecina de la del rico indiano:

La mayoría de los de Lugo procedían de las zonas de Vivero, Villalba, Chantada ... Unos embullaban a otros. Venía uno de una aldea, escribía que le iban bien las cosas y embullaba a otros familiares y vecinos, y así unos iban animando a otros. Éste ha sido uno de los errores que ha traído la emigración española a este país. Sobre finales de los años 40 y principio de los 50 comenzaron a regresar algunos como turistas, de visita, y a llevar algunos sus carros, que por esa época se les decía por las aldeas «haigas». Y claro usted llegaba con esos carros, todo poderoso, a su pueblo y por su presencia los demás calificaban a los otros emigrantes de ricos; los «americanos» o «cubanos» les decían entonces; aunque de cincuenta que se habían ido de la aldea a Cuba sólo regresara uno rico. Entonces qué sucede, que venía la ilusión, porque en Galicia todo el mundo se creía que era llegar aquí y hacerse rico, y eso no era así. Para hacerse rico había que trabajar mucho, ahorrar mucho y pasar muchos años, porque usted empezaba aquí a cero, primeramente tenía que aclimatarse, tenía que tener un punto de apoyo para que lo apoyaran. (E núm. 6. Alfredo: 1930 Becerreá-LU> 1957, La Habana, 25/10/97).

11 Monge Muley, 1953: 276. 
Efectivamente, la mayoría de los que regresaron lo hicieron derrotados, sin dinero, pero cargados con muchos cuentos fantásticos sobre las riquezas y bellezas de la isla y con la vestimenta urbana y tropical que utilizaban los domingos para asistir a las romerías y bailes de salón de las asociaciones regionales, que con el tiempo se convertían en harapos de la nostalgia cubana. Estos indianos de sainete influirán con sus atavíos habaneros y sus fantásticas y exageradas historias en la decisión migratoria de muchos jóvenes incautos y desesperados. El escritor cubano Lino Novás, nacido en una pobre aldea del norte de Galicia, retrata magistralmente al «habanero» derrotado cuando describe su patética despedida la víspera de la partida hacia Cuba en 1910, cuando sólo tenía siete años de edad:

«Era un hombre flaco, alto y encorvado de hombros, con bigotes largos y lacios. Vestía un traje de dril sucio y raído, con cuello de celuloide abierto, semejante a una corteza de árbol seco. En la cabeza traía un sombrero de pajilla y por debajo de él se le salían largas y veteadas quedejas grises. El hombre caminaba arrimado a un bastón tallado, y se quebraba al hacerlo por más debajo de la cadera. Al hablar lo hizo en castellano, con una voz forzada y sonora» ${ }^{12}$

Las fantásticas historias de estos indianos fantoches animaron a muchos jóvenes ingenuos a emprender la aventura de la emigración, como le ocurrió a José, bodeguero habanero natural del municipio coruñés de Rois:

Mi papá volvió ya viejo a Galicia y se casó con mi mamá. Mi papá no tenía tierra de labranza, mi mamá tenía algo pero no mucho, y entonces su modo de subsistir, y el nuestro, era el producto de las rentas de aquí. Y entonces, cuando yo cumplí 15 años, en el año 49, yo le dije a mi papá, embullao por los cuentos de los indianos como mi papá, que quería venirme para Cuba. Yo había oído de mi papá y de otros retornados que en Cuba no había pobres, que no había moneda de cobre y que corría el oro como el río. Entonces yo nací oyendo eso. Y en el 49 me vine a trabajar con los apoderados de mi papá, que eran a su vez parientes lejanos, primos segundos o terceros de nosotros (E núm. 44. José: 1935 Rois-C> 1949, La Habana, 18/7/98).

Este deslumbramiento ante el éxito del «triunfador» retornado se produjo incluso en casos en que la necesidad de emigrar no era acuciante. De este modo, algunos de los entrevistados afirman que su decisión de emigrar a Cuba fue generada más por las historias fantásticas de los retornados que por su extrema precariedad familiar. Así lo testimonia Bernardo de Mesía:

Yo vine por un embullo. Me embulló un hombre, de un pueblo colindante, un hombre que había estado aquí, que era incluso capataz. Me embulló, y entonces me vine para Cuba con él. Yo no sé chico. Incluso vino un pariente de nosotros también que era contratista de obras públicas y le dijo a mi padre:

12 Novas, 1990: 130. 
— ¡Déjalo conmigo de socio! Tiene que depositar 40.000 pesetas». Y entonces le dijo mi papá: — «Lo que Ud. quiera».

Pero yo le dije que no, que no me iba por dinero. Y entonces cogí y le dije a mi papá: — «Papi, si Ud. no me da permiso, yo me voy por la libre».

El embullo de muchachos. De aquella a los jóvenes nos embullaban con cuentos de caminos. (E núm. 48. Bernardo: 1908 Mesía-C> 1928, Camagüey, 7/12/97).

Sin embargo, como todos ellos comprobarían a su llegada a la isla, no era oro todo lo que relucía, ya que la mayoría de los inmigrantes no se enriquecieron, y los pocos que triunfaron lo hicieron a costa de mucho trabajo y de privaciones que ni siquiera habrían sufrido en su aldea, como relata Jesús, presidente de una de las numerosas asociaciones mutuales gallegas de referencia comarcal existentes en La Habana:

La emigración allá era por simpatía. Dejábamos lo conocido, las necesidades que había, pero no sabíamos lo que había aquí. Yo no conozco ningún emigrante que haya escrito una carta a la familia contando lo que verdaderamente había pasado aquí. Yo no conozco ningún emigrante que haya dicho que aquí trabajábamos 14 y 16 horas diarias, sin saber lo que era una novia, sin saber lo que era un fiesta, sin saber nada de nada, ni una diversión, ni nada. (E núm. 7, Jesús: 1924 Ourol-LU> 1949, La Habana, 28/10/97).

Aun así, cuando los «cuentos de indianos» no conseguían convencer a una gran parte de los campesinos, comenzaban a actuar los agentes a sueldo de las compañías navieras, de las empresas mineras y de la Asociación de Fomento de la Inmigración de Cuba. A la isla arribaron no pocos gallegos enrolados por los «ganchos» enviados a algunas comarcas de Galicia por las compañías norteamericanas Ponupo Manganese Company y The Spanish American Iron Company para trabajar en las minas de Daiquirí, Firmeza y el Cobre, situadas en las cercanías de Santiago de Cuba. Para la captación de mano de obra, estas compañías se valieron de la mediación de consignatarios de algunas comarcas del interior de Galicia, preferentemente de las provincias de Ourense y Lugo, que hasta la última década del siglo XIX no habían aportado grandes contingentes de emigrantes, y que, por lo tanto, no contaban con activas redes migratorias para facilitar el traslado a un gran número de emigrantes a la isla. No obstante, los incautos emigrantes, lejos de encontrarse con esas prometedoras condiciones laborales, de vivienda y manutención, tuvieron que soportar condiciones laborales de casi esclavismo, aislados en los poblados mineros de la sociedad cubana y sometidos a la dura disciplina laboral de la compañía y de la Guardia Rural a su servicio.

Pero la gravedad del estado en que se encontraban sus paisanos, noticia que llegaba desde Cuba a través de los testimonios de los retornados y de algunos artículos de la prensa española de La Habana, era opacada por engañosas 
campañas de prensa financiadas por diferentes compañías colonizadoras y mineras a través de la sociedad de Fomento de la Inmigración, constituida por la patronal cubana y aprobada por el Parlamento cubano el 18 de mayo de 1912. Éstos agentes reclutadores no sólo estaban al servicio de las grandes empresas cubanas, sino que también ejercían como agentes intermediarios de las concesionarias navales, y cuya tarea era reclutar el mayor número de pasajeros para los buques que éstas representaban. Estos «traficantes de carne humana», como los denominaba Castro López, eran los encargados de facilitar los documentos necesarios para el embarque ${ }^{13}$.

La mayoría de las víctimas de estos agentes de las compañías navieras eran jóvenes que pretendían huir del alistamiento militar y que temían ser enviados a Marruecos:

La emigración grande de gallegos vino a mediados del siglo pasado. Mi abuelo vino en el siglo pasado, a cortar caña (...), aunque se fue al poco tiempo para allá. Yo recuerdo que cuando vivimos en Orense de chiquitas, él nos cantaba unos cantos congos que él había aprendido de los morenos. Mi padre vino después, porque entonces iban para allá unos cuantos contratistas a embullar a los muchachos de allá a venir a Cuba a trabajar, porque a los muchachos los querían sacar de allí sus padres por lo de la guerra de Melilla. Entonces iban esos famosos contratistas y los sacaban, bajo cuerda, iban para el puerto de La Coruña o Vigo y montaban en el barco. Mi papá me contaba que entones en su pueblo había unos contratistas que sacaban a los muchachos por x cantidad de dinero, para que los dejaran montar en el barco para irse a Cuba. En la familia de mi papá eran seis varones y los seis se fueron de España y no hicieron el servicio militar. (E núm. 122. Olga: 1923 La Habana> 1937, La Habana 1/9/98).

Estos «contratistas», «ganchos» o «garroteros», como se les conocía generalmente en las aldeas gallegas, junto a la labor de atracción de candidatos a emigrar hacia las oficinas de determinadas concesionarias de compañías navieras, trataban de conducir a sus azorados clientes a ciertas fondas y pensiones del puerto de embarque con el fin de obtener una comisión de los posaderos. En muchas ocasiones los agentes clandestinos eran los propios hosteleros:

Los ganchos esos, eran los agentes que había cerca del puerto, que tenían su busca allí. Por lo regular, la mayoría tenían casas de huéspedes. Entonces los emigrantes iban a parar a su casa los días esos. Yo estuve allí y lo vi. [E núm. 1. José: 1907 Castroverde-LU> 1924, La Habana, 24/11/97].

Desde el decimonónico regionalismo romántico hasta el nacionalismo celtista del primer tercio del siglo XX es un lugar común de la literatura migratoria regional responsabilizar a un pretendido «afán de aventura» del pueblo ga-

13 Castro López, 1923: 61-62 
llego del éxodo masivo hacia América. Para Castelao, padre del nacionalismo gallego, sus paisanos, "de alma viaxeira», en su céltico «anceio do alén-mar» eran empujados a emigrar por causas imponderables ${ }^{14}$. Poco antes, a finales de los años veinte, Correa-Calderón defendía, frente a los argumentos demográficos de Unamuno, la misma teoría psicocultural del «instinto migratorio» de los pueblos celtas; «raza de los esforzados periplos» ${ }^{15}$ de la que supuestamente formaban parte sus paisanos. Sin embargo, este poético espíritu aventurero de los gallegos no era compartido por otros tratadistas más rigurosos, ni siquiera por algunos de los más irónicos escritores regionales. En 1920, Julio Camba, con su característica retranca galaica, contestaba así las teorías metafísicas de sus paisanos celtistas de la época:

«Hay quien atribuye la emigración de los gallegos a su sangre celta, y apoya esta opinión con el dato de que Irlanda ... es también pródiga en emigrantes. Yo no quiero negar el espíritu aventurero de la raza céltica, a la que según parece, tengo el honor de pertenecer; pero, ¿por qué es tan aventurera esta raza? En 1845 la patata irlandesa fue agostada por no sé qué enfermedad y desde entonces al 1850 más de un millón de irlandeses huyeron a los Estados Unidos. Los irlandeses se sintieron aquellos años más celtas que nunca. Después desapareció la enfermedad de la patata, y la emigración irlandesa disminuyó en un $80 \%$. Amigo lector; cuando vea usted a un celta migratorio, ofrézcale una patata, y al acto continuo, lo convertirá usted en un europeo sedentario. Las razas aventureras lo son por falta de patatas, por falta de pan, por falta de libertad» ${ }^{16}$.

Realmente, sólo hemos recogido un testimonio que confirme ese pretendido afán de aventura como desencadenante de su decisión de emigrar a Cuba: el de Severino, un marinero de la ría de Vigo, que, junto con otros jóvenes compañeros, decidió quedarse en Santiago de Cuba, después de la escala en su puerto del cablero británico en el que navegaban durante la Segunda Guerra Mundial, aunque seguramente, en plena posguerra, también echaban de menos las patatas, el pan y sobre todo la libertad:

En 1941 yo andaba embarcao en un cablero inglés, donde me metió mi suegro, y entonces llegamos a Santiago, y unos cuantos nos embullamos a quedarnos; otros dos y yo, el espíritu de la juventud. Uno de los que se quedó nos embulló a todos. Aquí no teníamos a nadie, nos quedamos a la aventura. (E núm. 75, Severino: 1919 Vigo > 1941, Boniato, 10/3/98).

14 Rodríguez Castelao, 1991: 208-209.

15 Correa-Calderón, 1929: 17.

16 Camba, 1920. 


\section{Causas y razones de la emigración femenina: reagrupación familiar}

Si para gran parte de los varones entrevistados la causa de su decisión migratoria oscilaba entre las necesidades económicas, la huida del servicio militar, la inducción y la emulación del indiano, para muchas de las mujeres fue el cuidado de algún familiar establecido en Cuba o la reagrupación familiar lo que las movilizó hacia la isla. De manera que numerosas entrevistadas aseguran que no llegaron a Cuba para trabajar sino más bien para ocuparse de la casa de algún familiar sin hijos, para hacerles compañía, o simplemente para visitarlos durante una temporada, aunque al final nunca regresaran a Galicia:

Llegamos el 10 de marzo de 1948, yo iba a cumplir 16 años. Yo vine con mi mamá, porque a mi tío se le había muerto la señora, y tenía dos hijos. Entonces él quería que una hermana suya le ayudase a cuidar su casa por un año. Entonces escribió a la hermana más joven para saber si nosotros vivíamos, pues desde la guerra no tenía noticias nuestras (...). Entonces mis abuelos pensaron en mi mamá, que estaba viuda ya (...). Y vinimos junto a mi tío. Yo no lo conocía, él llevaba treinta y pico años en Cuba y ya había perdido el contacto con la familia desde la guerra de España. Tuvo ese problema y fue que escribió. (E núm. 78. José Ramón: 1932 Muros-C> 1948, Santa Clara, 4/5/89).

Efectivamente, a partir de la década de los años treinta, que marca el fin de la emigración masiva gallega a Cuba, muchos emigrantes que comenzaban a envejecer sin haber constituido familia en la isla, reclamaron la compañía y los cuidados de sus hijas o de alguna hermana o sobrina:

Mi papá trabajaba en La Habana hasta que en el 28 volvió a España porque no se sintió bien y los médicos de acá le mandaron a otros médicos de Santiago de Compostela. Se quedó dos años en la aldea hasta que en el 32, cuando se repuso viró para Cuba, pero dejando embarazada a mi mamá... y soltera (...). Teníamos pocas tierras y había que trabajar en las casas de los vecinos. Ni a la escuela pude ir mucho tiempo, malamente aprendí a leer y escribir, y no sólo por tener que trabajar sino más bien por descuido de la familia; de las hembras no se ocupaban tanto como de los varones. Nosotras éramos para la casa, nos enseñaban a coser, a bordar, a cocinar y también a trabajar duro en el campo, como los varones, no es como aquí. Allí las mujeres son fuertes y no se asustan por el trabajo duro. ¡Cómo llevé cestos a la cabeza! ¡Y cómo me arrodillé para lavar en el río y en la fuente! Entonces mi tío, el hermano de mi papá, una vez que vino de visita a la aldea desde los EEUU, y vio aquello, me dijo: — «Qué va! Te voy a mandar a Cuba. Tú no puedes seguir en esta miseria, viviendo tu padre cómodamente en Cuba». Mi mamá y yo estábamos solas, y con pocas tierras, y en aquellos años después de la guerra (...) Y así es como vine a vivir con mi papá y su esposa que me trató como a una hija porque ellos no habían tenido hijos. Mi mamá se quedó allá. (E núm. 25 Francisca: 1930 A Mezquita-OR> 1949, Santa Clara, 3/5/98). 
No obstante, con la excusa de hacer compañía a sus familiares, en muchas ocasiones estas mujeres eran utilizadas como sirvientas para sus propios familiares, como sostiene el presidente de la asociación de los naturales de Viveiro en La Habana:

Aquí el padre, el tío o el hermano mandaban llamar a la hija, la sobrina o la hermana para que viniera a cuidarle. Es decir ya venía como sirvienta de su propia familia, era la servidumbre casera; que mientras sus familiares hombres trabajaban, ella atendía la casa e inclusive criaba los hijos de ese tío o hermano. Eran verdaderas criadas de la familia, y por lo general no se casaban. (E núm. 7, Jesús, 1924 Ourol-LU> 1949, La Habana, 28/10/97).

Esto es lo que le sucedió a Carmen, hija de unos comerciantes de Meira, que desembarcó en La Habana en 1930, cuando la emigración masiva a la isla comenzaba a desaparecer:

Yo misma me embullé a venir para Cuba. Llegué en el 30, con diecisiete años. Yo tenía al hermano mayor aquí, que cuando llegué tenían el niño de brazos. Entonces mi hermano no me dejaba trabajar, porque quería que me quedara en la casa a cuidar de su niño. Digo: — «Mira, yo no vine aquí a vivir de mano blanca». Entonces, cuando él estaba en el trabajo, me fui al reparto La Sierra a trabajar a casa de una familia que tenía dos niños. El trabajo me salió por un anuncio en el Diario de la Marina». (E núm. 63. Carmen: 1912 Meira-LU> 1930, La Habana, 17/4/98).

Muchas de las mujeres, y aquellos que llegaron de niños, lo hicieron a través de la reagrupación familiar, cuando generalmente el cabeza de familia, previamente instalado en la isla los reclamaba y financiaba su viaje. En estos casos la iniciativa partía de los familiares residentes en Cuba más que de los propios emigrantes reagrupados. Generalmente, el primero en venir era el padre de familia, que cuando ya contaba con un trabajo estable y tenía una vivienda, reclamaba a la esposa y a los hijos:

Vine cuando la Primera Guerra Mundial, en el año 15. Mi papá ya estaba aquí, tenía una finca ganadera cerca de Santiago. Mi mamá se había quedado allí porque tenía a mi hermana Amelia, que era muy niña, y no quiso arriesgarse a embarcar en un vapor con una niña tan chiquita. Entonces mi papá escribió a mi mamá para que viniéramos a Cuba, que ya los niños estaban grandes. Y con esas, aunque le daba miedo la guerra de Europa, mi mamá se embarcó con cinco niños (...) Papá estaba el pobre aquí y no le íbamos a dejar solo. El no quería virar a Galicia, parece que no le gustaba vivir allí. Él decía;

— «Yo allí no tengo perspectiva ninguna y aquí siempre voy viviendo y viviremos aún mejor». (E núm. 21. Aurora: 1904 Oleiros-C> 1915, Santiago de Cuba, 8/3/98).

Con todo, la mayor parte de las mujeres entrevistadas afirman haber emigrado empujadas, como los hombres, por la miseria y la búsqueda de mejores oportunidades laborales. 


\section{Causas y razones personales y familiares}

Pero, como hemos apuntado, no todas las causas que empujaron a emigrar tenían un origen económico, político o social. Un número destacable de las entrevistas resaltan que en muchos casos las condiciones económicas y sociales no fueron determinantes a la hora de decidirse a emigrar, sino que más bien fueron circunstancias familiares y estrictamente personales las que determinaron el embarque hacia Cuba.

La orfandad no aparece como una de las causas importantes del fenómeno migratorio en los trabajos sobre emigración, con todo, son numerosísimos los testimonios recogidos que aseguran que ésta fue la motivación principal de su decisión de emigrar. Motivo, por otra parte, estrechamente ligado a la necesidad económica más extrema. Unas veces, el emigrante se embarcaba con el progenitor superviviente y con sus hermanos, emprendiendo en otras ocasiones el trayecto migratorio individualmente, aunque en compañía de otros jóvenes de su generación. La muerte del cabeza de familia fue lo que precipitó a muchos jóvenes a lanzarse a la aventura de la emigración. Por lo general, estos huérfanos se dirigían a la protección de algún familiar próximo residente en la isla. La mayoría viajaron con su madre viuda y sus hermanos, reclamados por algún familiar establecido en la isla:

Mi papá cogió la gripe, esa mala del 18, y murió dejando a mamá desamparada. Así que nos vinimos con mis hermanos, que tenían una cuadrilla que hacía el ferrocarril de Oriente. (E núm. 106. Edesio: 1908 A Mezquita-OR> 1923, Camagüey, 6/12/97).

Mi papá había trabajado en Isabela de Sagua, donde tenía familia en el negocio del pescado. Luego volvieron a Ares y ahí nací yo. Pero mi papá muere después, quedando desamparados completamente; muy pobres. Era cuando Franco. Entonces, mi tío que era estibador en Isabela, nos reclamó, y vinimos los cinco hermanos con mi mamá a Cuba. (E núm. 51. Agustín: 1939 Ares-C> 1949, Cienfuegos, $6 / 5 / 98)$.

En otras ocasiones, la viuda se embarcaba sola, o acompañada de uno de los hijos de más edad, para trabajar de sirvienta y así poder mantener a los hijos pequeños que había dejado con la familia en la aldea, como hizo la madre de Evaristo, que en 1924, después de enviudar, dejó la villa de Chantada para instalarse en la capital cubana:

Mi padre murió cuando yo tenía siete años. Entonces se quedó mi mamá con cuatro chiquillos. Mi papá trabajaba en una fábrica de curtidos (...). Al morir él, mi madre no podía sostenernos, éramos cuatro. ¿Qué hizo? Teníamos parientes aquí en La Habana, hizo las gestiones y vino para Cuba, con la idea de trabajar aquí y mandar la mensualidad para los hermanos que quedaban allá. A mí, que era el mayor, me trajo con ella. Llegamos en el 24, yo tenía ocho años. Ella vino aquí a trabajar de 
sirvienta. Entonces, en la casa que se lo permitían, me tenía con ella, y cuando no, me dejaba en casa de unos parientes que teníamos aquí. Hasta que pasaron cuatro o cinco años, y entonces a mí me dejaron en una casa para que hiciera de mandadero, por la comida nada más, hasta que ella se juntó con un hombre, con un paisano de Chantada, pero no se casó, de aquella las mujeres no acostumbraban a casarse después de enviudar. Y entonces ya tuvimos una habitación para nosotros. (E núm. 65. Evaristo: 1916 Chantada-LU> 1924, La Habana, 14/11/97).

En otras ocasiones, era la muerte de la madre soltera la que provocaba la decisión de emigrar del huérfano, que salía de su aldea para buscar una nueva vida en Cuba. Así le ocurrió a Manuela, que, desesperada tras la muerte de su madre, se embarcó hacia la isla en compañía de un grupo vecinas de su parroquia de Outeiro de Rei:

Salí media loca de allá, que no sabía lo que hacía. Si no se muere mi madre, aunque me dieran oro molido... Yo no dejaba a mi madre por nada del mundo, hasta que Dios me la llevó, estuvo seis o siete meses enferma. Y aún enferma hacía todos los trabajos, conmigo siempre, buscando comida para los animales. Por la noche ella alumbraba la lamparita y sacaba la comida a las cerdas que estaban criando y se la daba a los pequeños, a los que estaban en el monte, caminando por afuera (...). Así que me vine con una prima hermana que ya había venido aquí antes y se había casado, y volvió con su esposo a Galicia. Y al pasar cinco meses cuando yo veía que ya iban a regresar me dije:

— «iAy caramba! Me voy a arreglar y me voy a ir para allá, porque aquí me la paso llorando y mirando a dónde estaba enterrada mi mamá»». (E núm. 8 Manuela: 1902 Outeiro de Rei-LU> 1922, La Habana, 26/2/98).

Por otro lado, las desavenencias familiares, tras el nuevo matrimonio del cabeza de familia viudo, fueron para algunos, como para Concha, de Cesuras, la principal motivación para emigrar; por llevarse mal con su madrastra o padrastro:

Yo tenía aquí una tía de mi mamá y unas primas hermanas de mi mamá, una de ellas fue en el cincuenta a Galicia, y oyendo yo sus cuentos ya comencé a idear venir a Cuba cuando fuese mayor. En el 54 fue la tía abuela y empezó a decirle a todas las sobrinas que por qué no iban con ella a Cuba, pero a mí nunca me dijo nada y a mí aquello me dolió. Pero bueno, ya de regreso a Cuba, le escribí una carta diciéndole mi deseo de ir allá, porque yo no me entendía muy bien con mi padrastro, que siempre andábamos regañados. Él tenía un carácter muy fuerte. Yo no llevaba bien el trato diferente que me daba respecto a mi hermana, que sí era hija suya, me sentía desplazada (...).

A los diecinueve ya me dieron permiso, me dijeron que me viniera para acá por cinco años, hiciera dinerito para fabricar una casa para la familia y después que volviera. Pero aquello no pudo ser porque en vez de ir a un país con posibilidades vine a Cuba, y, sin saberlo, me encontré con un país en revolución, era octubre del 58 , a poco más de dos meses de que triunfara la Revolución, y hacer dinero 
ya no era posible como antes. (E núm. 24. Concha: 1939 Cesuras-C $>1958$, Santiago de las Vegas, 27/7/99).

\section{Amor y desamor como causa de la decisión migratoria}

Si la orfandad fue para algunos la causa más importante de su decisión migratoria, para otros, curiosamente, el amor fue su principal impulsor. Para el párroco Castro López y el agrarista Villanueva la falta de hombres en el campo gallego, debido al éxodo masivo hacia América, fue la causa principal de que sus paisanas emigraran masivamente hacia América ${ }^{17}$. Y efectivamente, algunas entrevistadas aseguran que emigraron por amor, para poder casarse con el hombre que querían:

Yo tenía mi novio que, estaba aquí en Cuba, y nos queríamos casar. Él era de Iglesiafeita, de San Saturnino, cerca de Ferrol. Le conocí en Sobrado cuando volvió en un viaje de paseo, y me enamoré de él. Él ya aquí tenía una tintorería y era mayor que yo. Pero mis papás no querían que yo me casará con él porque yo era una niña de dieciséis años, pero yo me enamoré y quedé de acuerdo con él que vendría a Cuba en secreto. Así que yo no vine aquí a trabajar como otras, vine ya con compromiso de boda, aunque a lo mejor también hubiese venido como otras muchachas de por allí. (E núm. 27. Virtudes: 1908 Sobrado dos Monxes-C> 1925, Cienfuegos, 6/5/98)

Entonces vivíamos en El Ferrol, y yo no hacía nada, yo estaba allí en la casa con mi madre, con mi madrina y mis hermanas. Entonces me salió un novio cubano... Él era hijo de gallegos, y nos conocimos cuando tuvo que volver a España, cuando lo de la ley del cincuenta por ciento, y nos veíamos a escondidas o con la hermana de él, para no dar escándalo. Yo paseaba con mis hermanas por el Paseo Real, y él se acercaba a hablar conmigo, pero mi madre no quería que yo hablara con él porque era pobre. Luego, cuando estalló la guerra de España se volvió a Cuba, y desde La Habana, mandó a un hermano suyo que escribiera a mi madre una carta en la que decía: «Señora, deje casar a su hija con mi hermano, porque él la quiera a ella y ella le quiere a él». Mi mamá aceptó y nos casamos por poderes. (E núm. 108. Blandina: 1908 San Sadurniño-C> 1949, La Habana, 25/8/99).

En otras ocasiones eran los propios enamorados los que, contra la voluntad de sus progenitores, acordaban emigrar juntos con el fin de poder casarse en Cuba, como lo hicieron los padres de José:

Mi mamá tenía aquí un tío, y ella vino para la casa de él. Parece que mis papás ya se conocían de allá, y entonces mi mamá reunió dinero para venir a Cuba y mi papá también. Parece que quedaron de acuerdo para escaparse de allá y venir aquí para casarse (...). El tío, un día le dijo a mi mamá que él no estaba para cuidar a nadie. Le dio a entender que sabía que eran novios (...). Entonces se casó con mi papá

17 Castro López, 1923: 40-44; Villanueva, 1984: 273. 
y se fueron pá Santa Clara, al Central Washington. (E núm. 124. José: 1932 La Habana, La Habana, 12/10/97).

Otras veces era una proposición de un matrimonio arreglado la causa principal de la decisión migratoria, como fue el caso de Hortensia de $\mathrm{O}$ Incio:

Mi papá tenía un amigo que vivía aquí y que quería casarse conmigo. Entonces este señor me compró el pasaje de avión y me fue a esperar al aeropuerto. Él fue el que me reclamó para que yo pudiera venir. Ese gran amigo de mi padre respondía por mí. Este señor estaba ya instalado aquí, tenía una bodega, era del mismo pueblo que soy yo (...). La hermana trabajaba de ama de llaves en una casa rica y fue la que me buscó trabajo en otra casa como sirvienta. Él ya era una persona de edad. Él viniera aquí antes de yo nacer, y cuando volvió al pueblo, ya de mayor, vino a ver a mi padre y le animó a que me mandara a Cuba para trabajar como criada. Yo hice los trámites, él me reclamó, y ya. Él tenía intención de casarse conmigo, era ya viejo y se había quedado soltero, había trabajado toda la vida en la bodega, y no había salido de allí para poder ahorrar y volver a Galicia y casarse. Pero se le echó el tiempo encima. Yo era una muchacha de veintiún años, y a mí no me gustaban los viejos, así que encontré al que ahora es mi esposo y me casé. Él se quedó soltero. (E núm. 30 Hortensia: 1931 O Incio-LU> 1952, La Habana, 15/10/97).

Con menor frecuencia, algunas muchachas decidían emprender el trayecto migratorio para así alejarse de la imposición familiar de casarse con alguien que ellas no querían, como le ocurrió a Adela, que con diecisiete años decidió acompañar a su hermano a Cuba, que viajaba todos los años al inicio de la zafra y retornaba cuando ésta acababa:

Yo nací en la aldea de Mugares, en el municipio de Toén, muy cerquita de Orense. Mi padre era de familia rica de allí (...), tenía fincas individuales y una casa muy grande con un patio muy grande por donde entraban los carros cargados con leña, toxos y fentos del monte. Entonces andaba siempre mucha gente de fuera trabajando para la casa. Se recogía mucho vino, mucho maíz, muchas papas, un poco centeno, granos de toda clase, se cosechaban cebollas y ajos para todo el año. Yo vine con mi hermano y mi cuñada (...). Ellos vinieran muchas veces a Cuba a trabajar, y una de esas veces me invitaron a que me fuera con ellos, yo era la única que quedaba de la familia con mi mamá (...). Cuando llegué aquí me enamoré y me casé. A mi mamá no le gustó, porque quería que me casara con un vecino, pero a mí no me gustaba, por eso me vine con mi hermano. (E núm. 9. Adela: 1902 Toén-OR> 1919, La Habana, 21/10/97).

Otras mujeres solteras, más que por amor, afirman haber emigrado por desamor, por haberse quedado embarazadas. El sacerdote y sociólogo gallego Vales Failde ${ }^{18}$ constataba a principios del siglo XX, que entre los contingentes migratorios gallegos que se dirigían a América abundaban las mujeres

18 Vales Failde, 1902: 87-99. 
embarazadas, quienes cruzando el océano pretendían así alejar su deshonra, crearse una nueva vida en el país de destino y poder mantener a su hijo. Por la misma época, Castro López señalaba el hecho de que Galicia era la región española con más hijos naturales ${ }^{19}$. En los testimonios recogidos no son pocas las mujeres que afirman haber llegado a Cuba solteras y con sus hijos, y son muchos más los que afirman ser hijos de madre soltera. Valgan como muestra los casos de la madre de Modesta, tejedora de Celanova, que emigró con sus hijas en 1911, y de Dolores, campesina de Toén que llegó a la isla con su hija en 1942:

Mi mamá nos tuvo de soltera... Ya usted sabe. El que era nuestro papá, que era de allí mismo, se fue a Bilbao a trabajar a unas minas prometiéndole que volvería, pero no volvió. Ella trabajaba mucho tenía un telar de mano, no paraba y podía mantenernos a mi hermanita y a mí con lo que tejía y las pocas tierras que trabajaba. Ellos sembraban el lino, lo recogían, lo trataban y mi mamá lo hilaba y después lo tejía en su telar de mano. Nosotros vivíamos con mis abuelitos, mi abuelita murió primero y se quedó mi abuelito con nosotras. Bueno, mi mamá trabajaba mucho allá para poder mantenernos, y entonces el embullo de otras personas de la aldea que estaban en Cuba y que volvían y conversaban sobre lo que se ganaba acá y... Ya usted sabe, se embulló a venir para acá para darnos una vida mejor. (E núm. 17. Modesta: 1901 Celanova-OR> 1911, Camagüey, 6/12/97).

Yo trabajaba esos viñedos solita; cavaba las cepas, araba, echaba sulfato y vendimiaba, y la hija mía tenía ocho años y araba la tierra con una xugada de bueyes, y yo con vacas, porque las vacas siempre se torcían un poquito, y los bueyes iban más derechos. Yo quisiera que tú vieras a esa niña de ocho años arando con los bueyes, trabajando muy duro las dos solitas. Se me murieron los padres de jóvenes. Yo tenía un hermano que era comunista, y yo era la que le llevaba de comer a la sierra donde estaban las cuevas. La vida no es fácil (...). ¡Pasé tantas cosas! Y luego, quedar embarazada por ese maestro que me engañó. ¿Por qué ese padre no le puso el nombre a su hija? Había un cura por el medio, por eso no puedo verlos. El hermano, que era cura, debería haberle dicho:

- «Ponle el nombre a tu hija, no te importe ella, pero ponle el nombre a tu hija». Pero él no se lo puso, en esa amargura viví yo. Así que me vine con mis tíos que estaban viejos y no tenían hijos. (E núm. 114. Dolores: 1912 Toén-OR> 1942, La Habana, 23/8/99).

También algunas hijas de solteras emigraron a Cuba aconsejadas por sus propias madres, con el fin de que no les sucediera lo que a ellas, pudiendo sacarse así de encima el estigma de hijas de soltera, como le ocurrió a Ángela, que emigró aconsejada por su madre:

Pues mire usted, mi madre me tuvo de soltera y cogió miedo a que me ocurriera lo que a ella. Y por eso vine a Cuba, y me hizo jurar que tendría que casarme con un

19 Castro López, 1923: 46-47. 
hombre trabajador, aunque fuera pobre. Y entonces me dijo estas palabras, y me va a perdonar:

— «Si te lleva el demonio que te lleve en coche, porque para ser puta y no vender nada vale más ser mujer honrada».

Y esa palabra de honrada me mantuvo a mí firme. Por eso estoy en Cuba. (E núm. 10. Ángela: 1907 Lugo> 1927, La Habana, 27/11/97).

\section{FACTORES POSIBILITADORES DEL TRAYECTO MIGRATORIO: LAS CADENAS MIGRATORIAS}

De manera que, según los testimonios recogidos, las necesidades económicas, la falta de futuro para los jóvenes, la amenaza del servicio militar, la inducción, el espíritu aventurero y las circunstancias personales y familiares fueron, los principales factores de empuje de la emigración gallega a Cuba. Sin embargo, la mayoría de las personas que tuvieron que emigrar por alguna de estas causas, no habría podido hacerlo sin el factor posibilitador de las cadenas migratorias familiares y vecinale ${ }^{20}$ que unieron ciertas aldeas, parroquias y comarcas gallegas con algunas ciudades, comarcas y sectores laborales cubanos. Estas cadenas migratorias encauzaron y facilitaron el trayecto de miles de gallegos que lograron establecerse en la isla, gracias a la información proporcionada y a la financiación del viaje y al apoyo económico, laboral y afectivo que les brindaron ${ }^{21}$. A principios del siglo XX el gran propagandista de la emigración española a la Gran Antilla, Rafael M. ${ }^{a}$ de Labra, reconocía el protagonismo indiscutible de las cadenas familiares en el proceso migratorio español a

20 El concepto «cadena migratoria» como instrumento de análisis social apareció por primera vez en los estudios sociales en 1951 en la obra pionera del investigador neozelandés Lochore: «From Europe to New Zeland», 1951; siendo los Macdonald (1964) quienes la sistematizarán a partir de los años 60 en los estudios sociológicos anglosajones. Este instrumento de análisis sociológico no se generalizará en los estudios migratorios en español sino hasta finales de la década de los 80: Devoto y Rosoli, 1985 y Marquiegui, 1989.

21 Aunque el concepto «cadena migratoria» comienza a utilizarse sistemáticamente en los estudios migratorios gallegos a inicios de la década de los 90 (Vázquez, 1992, 2001), un año después de la obra pionera de Lachore, en Galicia aparece ya una investigación sobre la emigración española ultramarina que destaca el papel fundamental de estas cadenas en el proceso migratorio transatlántico: «En el problema de la elección del país, juegan principal papel las noticias llegadas a cada localidad española procedentes de los que emigraron antes, ocasionando al andar el tiempo, una clarísima ruta de cada pueblo o aldea de tradición emigratoria, hacia un determinado país americano, no siendo por ello extraño comprobar cómo localidades gallegas interdistantes apenas 10 kilómetros se separan en su proyección emigratoria a América tantos miles de kilómetros como puedan separar por ejemplo a Cuba de Argentina», Borregón, 1952. 
Cuba: «Nuestros emigrantes van a Cuba generalmente llamados por sus familias y allí encuentran siempre atención y preferencia, por motivos de sangre $»^{22}$. Sin embargo, no todas las cadenas migratorias que unieron España, y concretamente Galicia, con Cuba fueron exclusivamente familiares, pues las relaciones de paisanaje y vecindad fueron tan importantes o a veces más que aquéllas.

Un buen ejemplo de estas cadenas vecinales fue la que unió la comarca orensana de Viana do Bolo con la región central de Cuba, concretamente con Santa Clara y Ciego de Ávila, gracias al apoyo, entre otras, de la familia Prieto, exitosamente instalada en el sector de los productos petrolíferos y del alcohol, cuya distribución y venta monopolizaba en esas provincias, y que logró atraer a Cuba a muchos familiares y paisanos suyos:

Nosotros trajimos a mucha gente de la familia de allá, y los pusimos a trabajar con nosotros. También colocamos y ayudamos a muchos vecinos de allá. A muchos les prestamos dinero para que se establecieran como bodegueros y cantineros, que luego nos compraban las bebidas a nosotros. (E núm. 141. Fidel: 1899 Viana do Bolo-OR> 1915, Santa Clara, 1/5/98).

Muchas de estas cadenas migratorias lograron crear nichos laborales que controlaron desde finales del siglo XIX ciertas familias o naturales de algunas comarcas gallegas. Los propietarios, gerentes o incluso los propios trabajadores de esos nichos laborales trataban de emplear en el negocio a familiares y paisanos suyos en vez de a los cubanos nativos o a inmigrantes de ámbitos locales, comarcales o regionales ajenos. El control gallego de las bodegas y almacenes de víveres de toda la isla forma parte del imaginario popular cubano. Por lo general, estos bodegueros, almacenistas e importadores de víveres llegaban muy jóvenes a Cuba, casi unos niños, a trabajar de aprendices junto a un pariente, generalmente un tío materno, y cuando lograban establecerse por su cuenta mandaban llamar a sus hermanos más jóvenes, a sus sobrinos, o a hijos de sus vecinos de la parroquia natal; transmitiéndose así los puestos de trabajo en el sector comercial de unos familiares o vecinos a otros. José Adriano, natural de Ortigueira, como muchos comerciantes establecidos en Cuba, nos describe así la dinámica de estas cadenas familiares y vecinales que unían Galicia con el sector comercial cubano:

Cuba en esos pueblecitos tenía fama de ser un país rico. Hubo mucha emigración gallega para Cuba (...). Porque vinieron unos y trabajaron. Unos se metieron en el comercio, otros en fincas, otros en fábricas, y después trajeron familias, traían amistades de Galicia para trabajar aquí, porque de aquella no había problemas de

22 De Labra, 1910, p. 26. 
emigración aquí. El que tenía padrino aquí se bautizaba, venía para acá y trabajaba. $\mathrm{Y}$ a parte de eso venían muchas personas a trabajar a la agricultura: cortadores de caña, trabajaban en centrales y eso. Nosotros veníamos tan jóvenes porque naturalmente vinieron antepasados que trabajaron e hicieron capitales, montaron industrias, otros tenían fincas. El que venía, lo mismo se iba a trabajar en una tienda de ropa, que a un central que a la agricultura, porque si tenía un primo o un hermano, un pariente que tenía posibilidades de darle trabajo, ya venía asegurao (...).Yo tenía familia en Cuba. Tenía un tío, hermano de mi mamá, que era comerciante en el pueblo de Abreus, y me llamó para trabajar en la tienda mixta que tenía. Así era la cosa entonces. De aquella los que tenían comercio iban a pasear a Galicia y en su aldea hablaba con algún pariente o vecino y le decía:

— «Yo tengo un hijo que tiene catorce años ...».

Y todos tenían la ilusión de mandarlo para acá porque el que venía para acá, el 80 o $90 \%$, hacía capital, porque trabajaban. (E núm. 39. José Adriano: 1909 Ortigueira-C> 1922, Cienfuegos, 8/5/98).

El funcionamiento de estas cadenas migratorias se basaba, pues, en lazos solidarios entre familiares y vecinos, que se iniciaban con la financiación del pasaje del pariente que quería emigrar y continuaba en la isla con la inmediata inserción laboral de éste. Seguidamente, el recién llegado, una vez establecido, comenzaba a financiar el proyecto migratorio de otro familiar más joven, y así sucesivamente:

Mi papá era el menor de cuatro hermanos que había (...). Cuando llegó el primero, que era sastre, vino con el compromiso de pagar el pasaje a sus papás que habían contribuido a pagárselo y a su vez a pagar el pasaje del próximo, y el otro del próximo y así sucesivamente. Fue una aventura, un salto. Ya cuando el sastre vino mandó a buscar al segundo y después éste el tercero, y mi papá vino el último. Llegó en el 98. Papá asistió aquí, según él me decía, cuando andaban en la guerra y cuando la gente gritaba; «Viva Cuba libre». O sea, mi papá estuvo bajo el gobierno español, bajo la intervención norteamericana y bajo el gobierno cubano. (E núm. 44. José: 1935 Rois-C> 1949, La Habana, 18/7/98).

Mi papá vino a Cuba cuando la Guerra de Independencia y luego regresó y se casó en la aldea y dejó a mi mamá allá a cargo de todos nosotros. Iba y venía cada unos cuantos años. Luego a medida que crecíamos iba trayendo un hijo. En cada viaje, a la vuelta, traía uno, y nos pagaba el pasaje con la ayuda de los otros hermanos que ya estaban en el comercio en La Habana. (E núm. 7. Jesús: 1924 Ourol-LU> 1949, La Habana, 28/10/97).

Pero no todas las cadenas migratorias tenían como destino el sector comercial. Existieron en Cuba algunas actividades laborales controladas por los naturales de ciertas comarcas gallegas que fueron la meta laboral de cientos de emigrantes procedentes de esas zonas. Éste era el caso de los jardineros del cementerio Colón, ocupación en la que los naturales de algunas parroquias del valle del Ulla, de los municipios de A Estrada, Silleda y Vedra aún a finales del siglo XX eran mayoría: 
Aquí en el cementerio, antes de que llegaran mi padre y mi tío, ya había muchos de la Estrada trabajando. Cuando yo llegué había por arribita de 40 y pico de allí trabajando en el cementerio de una plantilla de 120. Yo calculé que había unos 70 gallegos, la mayoría de Pontevedra (...).Había muchos de la parroquia nuestra de Arnois, y de Oca, de Loemil, Berres, Riobó, Sia, San Miguel de Castro, Ribadulla... Yo entiendo que unos habían traído a otros. (E núm. 5 Alfonso: 1929 A Estrada-PO> 1947, La Habana, 6/11/97).

Estas cadenas de origen familiar y vecinal ya existían desde las últimas décadas de la Colonia, no se interrumpieron durante la ocupación norteamericana y se activaron aún más tras la proclamación de la República de Cubana:

Mi papá vino aquí ocho veces. A la vuelta de cada viaje a Galicia trajo un hijo. Mi papá vino a Cuba por primera vez después de la guerra de Independencia, a principios de siglo, sobre 1908, 1910. Él ya tenía a su vez mucha familia en Cuba; hermanos, primos... Uno de ellos ya estaba bien situado aquí, tenía una buena mueblería, había venido antes de la guerra de Independencia. Luego mi papá se casó allá y nos fue trayendo uno a uno a los ocho hermanos. Yo personalmente no me puedo quejar, porque mis hermanos, los que vinieron primero, me ayudaron mucho; para mí realmente fue un cambio de casa y no un cambio de familia. (E núm. 7, Jesús: 1924 Ourol-LU> 1949, La Habana, 28/10/97).

En definitiva, podemos afirmar que estas cadenas migratorias fueron el factor que más emigrantes gallegos encaminó hacia Cuba, y el que consiguió que este grupo regional fuese el más numeroso y extenso de todos los colectivos españoles de la isla.

En conclusión, si bien la gran mayoría de los gallegos que emigraron a Cuba lo hicieron por motivos económicos, muchos de ellos fueron empujados también por causas psicosociales y circunstancias personales, e incluso algunos por situaciones afectivas, viéndose facilitado el trayecto migratorio de todos por activas cadenas y redes migratorias de tipo familiar y local, sin las cuales los contingentes migratorios hacia Cuba no hubiesen sido tan masivos. Sin duda, estas mismas causas de empuje y factores posibilitadores de la emigración se podrían aplicar también a los procesos migratorios de las demás regiones españoles en la fase de emigración masiva hacia América.

\section{BIBLIOGRAFÍA}

Borregón Ribes, Vicente, La emigración española a América, Vigo, Imprenta Faro de Vigo, 1952.

Camba, Julio, Eco de Galicia, La Habana, 21/3/1920.

Castro López, R., La emigración en Galicia, La Coruña, Tip. El Noroeste, 1923. 
Castro, Rosalía, Follas Novas, Obra poética, Madrid, Espasa Calpe, 1968.

Correa-Calderón, E., Índice de utopías gallegas, Madrid, CIAP, 1929.

Devoto, F. y Rosoli (eds.), La inmigración italiana en la Argentina, Buenos Aires, Biblos, 1985.

Eiras Roel, A. (coord.), Emigración española y portuguesa a América, Alicante, Diputación de Alicante, 1991.

Ferreiro, Celso Emilio, Curros Enríquez, Madrid, Júcar, 1976.

Labra, Rafael M. ${ }^{\mathrm{a}}$ de, Cuba como país de inmigración, memoria, Madrid, Tip. de Alfredo Alonso, 1910.

Lochore, Revel Anson, From Europe to New Zealand, Wellington, A. H \& A. W. Reed / New Zealand Institute of International Affairs, 1951.

Manifiesto para la Solidaridad Gallega, La Coruña, Tip. F. García Ybarra, 1907.

Marquiegui, D. N., «La inmigración española en Luján. Una aproximación, (1880-1920)», Estudios Migratorios Latinoamericanos, n. ${ }^{\circ} 3$ (Buenos Aires, diciembre 1989): 48-61.

Mella, Ricardo, «El problema de la emigración en Galicia», en Ensayos y conferencias, Gijón, Tip. La Industria, 1934. (Primera edición, Barcelona, Imp. Ortega, 1885).

Monge Muley, Servando y Gerardo, Los españoles en Cuba, Barcelona, 1953.

Novás, Lino, Obra narrativa, La Habana, Letras Cubanas, 1990.

Risco, Vicente, O problema político de Galiza, Vigo, Ed. Sept, 1976. (Primera edición en castellano, Madrid, CIAP, 1930).

Rodríguez, F., Análise sociológica da obra de Rosalía de Castro, Vigo, AS-GP, 1988.

Rodríguez Castelao, Alfonso, Sempre en Galiza, Vigo, Biblioteca de Autores Galegos, 1991.

Sánchez-Albornoz, N., Españoles Hacia América. La emigración en masa, 1880-1930, Madrid, Alianza Ed., 1988.

Vales Failde, J., La emigración gallega, Madrid, Tipografía Antonio Haro, 1902.

Vázquez A., «Causas de la emigración y tipología de emigrantes», Historia general de la emigración española a Iberoamérica, Madrid, CEDEAL, Comisión Quinto Centenario, 1992: 201-240.

Vázquez, A., «La salida», Historia general de la emigración española a Iberoamérica, Madrid, CEDEAL, Comisión Quinto Centenario, 1992: 241-258.

Vázquez, A., «Factores de empuje y condiciones de transporte de Galicia hacia el Río de la Plata (1850-1930)», NúÑEz SEIXAS, X. M., La Galicia austral, Buenos Aires, Biblos, 2001: 53-68. 
Vidal Rodríguez, José Antonio, La emigración gallega a Cuba: trayectos migratorios, inserción y movilidad laboral. 1898-968, Madrid, CSIC, 2005.

Villanueva, Valeriano, Medios prácticos más eficaces de impulsar el progreso moral de Galicia, Madrid, Xunta de Galicia, 1984. (Obra original, Madrid, Tipografía Jaime Ratés, 1918).

Yáñez, C., La emigración española a América: $s$. XIX-XX. Dimensión y características cuantitativas, Gijón, Archivo de Indianos, 1994.

\section{ENTREVISTAS}

41 entrevistas: 25 hombres y 16 mujeres; 39 nacidos en Galicia y 2 descendientes nacidos en Cuba: 13 de Ourense, 13 de A Coruña, 10 de Lugo y 3 de Pontevedra.

E núm. 1. José: 1907 Castroverde (Lugo)> 1924. Registrada en La Habana, 24/11/97.

E núm. 4. Augusto: 1906 Ortigueira (A Coruña)> Emigró en 1925. Registrada en La Habana, 25/11/97.

E núm. 5. Alfonso: 1929 A Estrada (Pontevedra). Emigró en 1947. Registrada en La Habana, 6/11/97.

E núm. 6. Alfredo: 1930 Becerreá (Lugo). Emigró en 1957. Registrada en La Habana, $25 / 10 / 97$

E núm. 7. Jesús: 1924 Ourol (Lugo). Emigró en 1949. Registrada en La Habana, 28/10/97.

E núm. 8 Manuela: 1902 Outeiro de Rei (Lugo). Emigró en 1922. Registrada en La Habana, 26/2/98.

E núm. 9. Adela: 1902 Toén (Ourense). Emigró en 1919. Registrada en La Habana, 21/10/97.

E núm. 10. Ángela: 1907 Lugo. Emigró en 1927. Registrada en La Habana, 27/11/97.

E núm. 12. María: 1904 A Estrada (Pontevedra). Emigró en 1929. Registrada en La Habana, 6/4/98.

E núm. 16 Antonio: 1908 Carballeda de Avia (Ourense). Emigró en 1922. La Habana, 8/12/97.

E núm. 17. Modesta: 1901 Celanova (Ourense). Emigró en 1911. Registrada en Camagüey, 6/12/97.

E núm. 21. Aurora: 1904 Oleiros (A Coruña). Emigró en 1915. Registrada en Santiago de Cuba, 8/3/98.

E núm. 23. Aurora: 1914 Palas de Rei (Lugo). Emigró en 1925. Registrada en La Habana, 10/2/98.

E núm. 24. Concha: 1939 Cesuras (A Coruña). Emigró en 1958. Santiago de las Vegas, $27 / 7 / 99$. 
E núm. 25. Francisca: 1930 A Mezquita (Ourense). Emigró en 1949. Registrada en Santa Clara, 3/5/98.

E núm. 27. Virtudes: 1908 Sobrado dos Monxes (A Coruña). Emigró en 1925. Cienfuegos, 6/5/98.

E núm. 30. Hortensia: 1931 O Incio (Lugo). Emigró en 1952. Registrada en La Habana, $15 / 10 / 97$.

E núm. 39. José Adriano: 1909 Ortigueira (A Coruña). Emigró en 1922. Registrada en Cienfuegos, 8/5/98.

E núm. 40. José: 1904 Coristanco (A Coruña). Emigró en 1924. Registrada en Trinidad, 7/7/99.

E núm. 42. Ramón: 1903 Castrelo de Val (Ourense). Emigró en 1919. Las Tunas, $31 / 7 / 99$.

E núm. 43. Francisco: 1909 Valdoviño (A Coruña). Emigró en 1935. Registrada en Santa Clara, 1/5/98.

E núm. 44. José: 1935 Rois (A Coruña). Emigró en 1949. Registrada en La Habana, $18 / 7 / 98$

E núm. 48. Bernardo: 1908 Mesía (A Coruña). Emigró en 1928. Registrada en Camagüey, $7 / 12 / 97$.

E núm. 51. Agustín: 1939 Ares (A Coruña). Emigró en 1949. Registrada en Cienfuegos, 6/5/98.

E núm. 63. Carmen: 1912 Meira (Lugo). Emigró en 1930. Registrada en La Habana, $17 / 4 / 98$

E núm. 65. Evaristo: 1916 Chantada (Lugo). Emigró en 1924. Registrada en La Habana, $14 / 11 / 97$.

E núm. 66. Carmen: 1905 Sarria (Lugo). Emigró en 1923. Registrada en La Habana,24/10/97.

E núm. 71. José: 1922 Parada de Sil (Ourense). Emigró a Cuba en 1949. Santa Clara, 1 $5 / 5 / 98$

E núm. 75, Severino: 1919 Vigo (Pontevedra). Emigró en 1941. Registrada en Boniato, $10 / 3 / 98$.

E núm. 78. José Ramón: 1932 Muros (A Coruña). Emigró en 1948. Registrada en Santa Clara, 4/5/89.

E núm. 79. Antonio: 1936 Nogueira de Ramuín (Ourense). Emigró en 1951. Santa Clara, 2/5/98.

E núm. 98. Antonio: 1902 Pontedeume (A Coruña). Emigró en 1920. Registrada en Sagua la Grande, 5//5/98.

E núm. 100. Jesús: 1904 Gomesende (Ourense). Emigró en 1920. Registrada en Morón, 3/12/97.

E núm. 101. Manuel: 1914 Amoeiro (Ourense) > 1930. Registrada en, La Habana, 3/3/98. 
E núm. 106. Edesio: 1908 A Mezquita (Ourense)> 1923. Registrada en Camagüey, $6 / 12 / 97$.

E núm. 122. Olga: 1923 La Habana, hija de orensanos. Registrada en La Habana, $1 / 9 / 98$.

E núm. 108. Blandina: 1908 San Sadurniño (A Coruña). Emigró en 1949. Registrada en La Habana, 25/8/99.

E núm. 114. Dolores: 1912 Toén (Ourense). Emigró en 1942. Registrada en La Habana, 23/8/99.

E núm. 124. José: 1932 La Habana. Registrada en La Habana 12/10/97.

E núm. 141. Fidel: 1899 Viana do Bolo (Ourense). Emigró en 1915. Registrada en Santa Clara, 1/5/98.

E núm. 145. Manuel: 1897 A Peroxa (Ourense). Emigró en 1911. Registrada en Holguín, 2/8/97.

\section{CAUSES AND FACTORS OF THE MIGRATORY PROCESS IN THE EMIGRANTS' DISCOURSE: GALICIANS IN CUBA IN THE FIRST HALF OF THE 20th CENTURY}

Based on different scholars' works of the 19th and 20th centuries as well as on oral testimonies collected in Cuba, I intend to show in this paper that besides the purely economic reasons, there were also other psychosocial and frequently decisive factors involved in the final decision of a significant number of Galicians who emigrated to Cuba, without which they would probably have never decided to leave their homes. This fact might also be applied to other migratory processes of other Spanish regions during the period of Spaniards' mass emigration to America.

KEY WORDS: Galicia, Cuba, oral history, migratory causes and factors. 